\title{
Cyberbullying y Ciberviolencia de pareja en alumnado de una universidad privada mexicana
}

\section{Cyberbullying and Cyber Dating Abuse in Students of a Private Mexican University}

\author{
Ricardo J. Romo-Tobón \\ Universidad Popular Autónoma del Estado de Puebla, Puebla, México. \\ ORCID: https://orcid.org/0000-0003-3945-7852 \\ Valeria Vázquez-Sánchez \\ Universidad Popular Autónoma del Estado de Puebla, Puebla, México. \\ ORCID: https://orcid.org/0000-0002-7126-7357 \\ José L. Rojas-Solís* \\ Benemérita Universidad Autónoma de Puebla, Puebla, México. \\ ORCID: http://orcid.org/0000-0001-6339-4607 \\ Salvador Alvídrez \\ Universidad de Monterrey, Nuevo León, México \\ ORCID: http://orcid.org/0000-0002-2707-5171
}

Recibido 30-03-19 Revisado 20-04-19 Aprobado 22-07-19 En línea 30-07-19

*Correspondencia

Email: jlrojassolis@gmail.com
Citar como:

Romo-Tobón, R., Vázquez-Sánchez, V., Rojas-Solís,

J.L., \& Alvídrez, S. (2020). Cyberbullying y

Ciberviolencia de pareja en alumnado de una universidad

privada mexicana. Propósitos y Representaciones, 8(2),

e303. doi: http://dx.doi.org/10.20511/pyr2020.v8n2.303 


\section{Resumen}

La ciberviolencia en adolescentes y jóvenes es un tema que ha llamado recientemente la atención de la comunidad científica, se trata de un fenómeno relativamente nuevo y creciente que se ha desarrollado a la par del uso de las Tecnologías de la información y la comunicación; añadido a ello, actualmente la literatura disponible sobre esta temática en el contexto mexicano aún sigue siendo escasa. Por tanto, esta investigación se dirigió a analizar la presencia y asociación de cyberbullying y ciberviolencia en la pareja en una muestra de 299 estudiantes de una universidad privada mexicana (183 mujeres y 116 hombres) quienes contestaron el Cuestionario de cyberbullying y el Cuestionario de abuso on-line en el noviazgo. De acuerdo con los resultados obtenidos se observó la presencia de ambos fenómenos, que los varones reportaron sufrir y perpetrar con mayor frecuencia ciberviolencia de pareja en la modalidad de agresiones directas, además se hallaron correlaciones entre ambos fenómenos. A la luz de los resultados obtenidos tanto mujeres como hombres parecen ser víctimas y agresores, sobre todo en conductas relativas al control de la pareja, asimismo el cyberbullying y ciberviolencia estuvieron relacionados, aunque con una menor fuerza de asociación.

Palabras clave: Violencia; Acoso; Relaciones interpersonales; Universidad; México.

\section{Summary}

The cyber-violence in adolescents and young people recently has attracted the attention of the scientific community, it is a relatively new and growing phenomenon that has developed along with the use of Information and Communication Technologies. Besides, data currently available in this subject in the Mexican context is still scarce. Therefore, this research analyzes the presence and association of cyberbullying and cyber-violence in the couple in a sample of 299 students from a private Mexican university (183 women and 116 men) who answered the Cyberbullying Questionnaire and the Cyber dating abuse questionnaire among young couples. According to the results obtained, the presence of both phenomena was observed, men reported suffering and perpetrating with greater frequency cyberviolence of couple in the direct aggression modality, in addition correlations were found between both phenomena. In conclusion, both women and men seemed to be victims and aggressors, especially in behaviors related to the control of the couple, also cyberbullying and cyberviolence were related, although with a lower strength of association.

Keywords: Violence; Peer Harassment, Interpersonal Relations, University, Mexico

\section{Introducción}

Hoy en día la tecnología es uno de los recursos más utilizados por los seres humanos y sin duda ha logrado permear en la vida cotidiana debido, principalmente, a las actuales necesidades y estilos de vida. En el caso específico de los estudiantes universitarios, estos medios se han vuelto atractivos como facilitadores de diversas actividades diarias teniendo un alto impacto en las mismas y, sobre todo, en las relaciones sociales que se han empezado a caracterizar por la accesibilidad a la internet y al uso casi ininterrumpido de los teléfonos móviles facilitando así la comunicación a través de aplicaciones y redes sociales (Nobles et al., 2016).

En este sentido, diferentes investigaciones destacan que para los jóvenes y adolescentes, las redes sociales virtuales se han vuelto primordiales para la formación de grupos y el desarrollo de relaciones interpersonales (Martínez-Ferrer \& Moreno, 2017) llegando, incluso, a reconocer que dichas redes son indispensables para la comunicación con sus amigos y compañeros para estar en contacto y mantener una vida social plena (Espinar \& González, 2009); sin excluir que 
también se convierten en una herramienta para la vivencia del amor y la pareja, afectando no solo el contacto on-line, sino también la interacción off-line (Rodríguez \& Rodríguez, 2016).

Si bien, en un inicio estas interacciones virtuales poseían una connotación positiva para la mejora de las relaciones y la comunicación, las investigaciones recientes concuerdan en que esto no siempre sucede así, pudiendo aparecer conductas violentas tanto hacia compañeros como hacia la propia pareja (Nobles et al., 2016; Doucette et al., 2018). En concreto, han comenzado a surgir nuevas conductas y formas de expresión de la violencia a través de medios digitales debido al uso inadecuado de las Tecnologías de la Información y Comunicación [TIC's] en las actividades cotidianas y por los cambios en las interacciones y formas de relacionarse entre los individuos (Bernal \& Angulo, 2013; Mitchell, Tulane, Porter \& Beckert, 2017).

Ahora bien, podría esperarse que los estudiantes universitarios presenten un mayor nivel de madurez emocional que les permita iniciar y mantener relaciones interpersonales más saludables y con una mayor estabilidad, siendo capaces de reconsiderar, renegociar y adaptar las mismas (Papalia, Feldman \& Martorell, 2012), no obstante, Rodríguez \& Rodríguez, (2016) encontraron que el uso de las TIC's en ocasiones pueden ser generadoras de conflictos y que los jóvenes llegan a tolerar, minimizar o perpetrar actos de vigilancia, intrusión o control con -al parecer- poco sentido de autocrítica o baja conciencia de estos como actos violentos.

En ese contexto de ideas es preciso señalar que el cyberbullying y la ciberviolencia de pareja se encuentran dentro de "nuevos" tipos de violencia virtual que encuentran no pocas dificultades para su estudio, prueba de ello es la carencia de definiciones concretas o teorías explicativas para estos fenómenos ubicándolos en una "zona gris" donde se puede hallar una perspectiva teórica (López, Juárez \& Acevedo, 2014) y generalizaciones empíricas (Hernández, Fernández \& Baptista, 2014) basadas en las hipótesis y resultados de investigaciones hechas al respecto (Costa \& Ferreira, 2018, Gámez-Guadix, Borrajo \& Calvete, 2018). Por tanto, el presente estudio se dirige a aportar algunas regularidades empíricas que puedan formar parte del marco teórico de subsecuentes investigaciones en la materia (Sautu, Boniolo, Dalle \& Elbert, 2005).

\section{Argumentación}

\section{Cyberbullying (Ciberacoso)}

Una de las primeras problemáticas que se presentan al hablar de cyberbullying es que se pueden hallar dos posturas distintas de estudio. La primera hace referencia a este tópico como una extensión de los comportamientos del acoso o bullying, con la única distinción de que estas conductas se traslapan al ámbito virtual (Castellanos, Vila \& Gámez-Guadix, 2016), mientras que la segunda busca reconocerlo como un fenómeno independiente, puesto que considera que existe un impacto más significativo debido a que las características de la víctima, agresor y espectador son distintas a las que se contemplan dentro del acoso off-line (Peter \& Petermann, 2018).

En ese orden de ideas e intentando acotar el concepto, algunos autores lo han definido como formas de hostigamiento que realiza un sujeto o un grupo utilizando las TIC's, principalmente la internet y el teléfono móvil con la intención de dañar a otro igual, pero con escasas posibilidades de defenderse debido al anonimato que le dota el medio virtual (Garaigordobil \& Aliri, 2013; Martínez-Otero, 2017). Asimismo, también se le ha considerado como parte de la violencia psicológica-relacional, dado que las conductas están encaminadas a perjudicar a otro emocionalmente o a generar temor ante la amenaza constante de un daño mayor, haciendo uso principalmente de la difamación, aislamiento o manipulación (Cowie, 2013; Rodríguez-Domínguez, Durán \& Martínez-Pecino, 2017).

En suma, el cyberbullying tiene múltiples manifestaciones lo que a su vez ha complicado que se aglutinen comportamientos concretos dentro de este fenómeno (Peter \& Petermann, 2018), no obstante, autores como Cowie (2013) y Hernández \& Solano (2007) mencionan que algunas conductas que podrían considerarse dentro de este fenómeno son; el envío de mensajes con 
insultos o con cualquier tipo de amenaza, la difusión de rumores, el envío y/o publicación de fotos o videos de situaciones desagradables para la persona agraviada, el compartir información personal sin consentimiento e incluso la exclusión de la comunicación a través de los medios digitales.

Aunado a ello, también se ha buscado exponer sus características. En este sentido, de acuerdo con Hernández \& Solano (2007), el cyberbullying se caracteriza por ser un acto de violencia encubierto que presupone el dominio y uso de las TIC's, que invade la privacidad y vulnera la seguridad de la persona afectada. Igualmente, Cerezo-Ramírez (2012) menciona que dichos comportamientos pueden manifestarse de manera directa e indirecta, con un amplio espectro de consecuencias, a una alta velocidad de difusión, sin requerir ni tiempo ni espacio específico.

De manera más concreta, se puede destacar el anonimato del agresor y la sensación de impunidad que ello le genera, provocando incluso una normalización de la agresión al no existir una consecuencia a esta acción. Asimismo, la aparición de este tipo de violencia puede aumentar puesto que, al no tener una víctima presencial, al agresor se le dificulta aún más empatizar con sus víctimas, desconociendo en muchas ocasiones la gravedad del daño que provocan (MartínezOtero, 2017).

En la presente investigación se considera al cyberbullying como una extensión del bullying a través de conductas de acoso que generan una amplia sensación de indefensión e impotencia en la víctima, debido al uso de las TIC's, y donde además se cuenta con una rápida difusión a una amplia audiencia (Cerezo-Ramírez, 2012). Añadido a ello es importante indicar la relación entre el bullying y el cyberbullying, así las conductas de bullying físico por lo general tienden a ser un factor predictor de las conductas de cyberbullying, sin embargo, esto no sucede a la inversa; de la misma manera que la victimización previa representa un factor de riesgo importante en la futura aparición de ambos tipos de acoso (Del Rey, Elipe \& Ortega-Ruiz, 2012).

\section{Ciberviolencia de pareja.}

De manera similar a lo que ocurre con el cyberbullying, la ciberviolencia de pareja se encuentra en una encrucijada con respecto a su definición (Backe, Lilleston \& McCleary-Sills, 2018), empero autores como Lucio-López \& Prieto-Quezada (2014) consideran que se trata de conductas derivadas de la violencia física que puede presentarse dentro de las relaciones de noviazgo. Se trata de un nuevo acontecimiento que ha sido el objetivo de diversos estudios (Borrajo \& Gámez-Guadix, 2016; Borrajo, Gámez-Guadix \& Calvete, 2015; Vagi, OMalley, Basile \& Vivolo-Kantor, 2015) y que, al igual que el cyberbullying, ha ganado terreno con lo que Mitchell, et al. (2017) llaman "convergencia tecnológica" que básicamente se define como "la emergencia de nuevos dispositivos que proveen acceso a medios tecnológicos y de entretenimiento" (Mitchell et al., 2017, p. 3). En otras palabras, su aparición se incrementa en la medida que el acceso a la tecnología y redes de comunicación se va facilitando, particularmente en poblaciones adolescentes y de adultos jóvenes. Propiamente, no existe una definición concreta de lo que se considera ciberviolencia, sin embargo, para los propósitos de la presente investigación se considerarán las propuestas de Yahner, Dank, Zweig, \& Lachman, (2014) al igual que Gámez- Guadix et al. (2018) para construir la siguiente definición: todas aquellas conductas que buscan controlar, humillar, herir, exponer, ridiculizar o aislar a un miembro de la pareja a través de la utilización de las TIC's (correo electrónico, redes sociales, mensajería instantánea, fotografias, vídeos etc.). Una de las principales características de este "nuevo" tipo de violencia, es que puede ocurrir en cualquier momento y en cualquier lugar, por lo que compartir el mismo espacio físico con otro individuo deja de ser una limitante.

Finalmente es importante mencionar que al ser un fenómeno que se ha desarrollado con el aumento en el uso de las TIC's, existe una elevada probabilidad de que no solo se trate de un potencial problema de salud pública en un futuro cercano, sino que también por la facilidad de acceso a redes y dispositivos posiblemente se incrementará su presencia en franjas etéreas cada vez menores. 
Por lo anterior, son varias las razones para llevar a cabo esta investigación, en primer lugar, se encuentra el avance e incremento del acceso a nuevas tecnologías, su integración a la vida cotidiana, las interacciones interpersonales y, por extensión, al desarrollo de las relaciones de noviazgo. En segundo lugar, el aparente incremento de conductas violentas on-line y su bidireccionalidad, es decir que tanto víctimas como agresores padecen y replican dichas conductas. Tercero, la escasez de información en el contexto latinoamericano y más particularmente en el contexto mexicano. Y, finalmente, el hecho de que la información disponible, en su mayoría, implica investigaciones enfocadas únicamente en uno de los dos fenómenos, que solo consideran su prevalencia, pero no necesariamente su vinculación, sin olvidar que en su mayoría se focalizan en poblaciones adolescentes.

En ese sentido, la pregunta de investigación del presente estudio ha sido: ¿Cuál es la prevalencia y asociación entre cyberbullying y la ciberviolencia de pareja en una muestra universitaria?

De igual manera se plantearon los siguientes objetivos: 1) identificar cuáles son las conductas que se presentan con mayor y menor frecuencia, tanto en hombres como en mujeres, en ambos fenómenos; 2) conocer si existe una diferencia estadísticamente significativa entre las respuestas dadas por ambos sexos con respecto al cyberbullying y ciberviolencia tanto sufridos como cometidos, y 3) determinar si existe correlación estadísticamente significativa entre ambos tipos de violencia.

\section{Método}

\section{Población}

La presente investigación se desarrolló bajo un enfoque cuantitativo, transversal con alcance exploratorio, descriptivo y correlacional. Participaron 299 jóvenes mexicanos universitarios, de los cuales fueron 186 mujeres y 116 hombres, de nivel socioeconómico medio y medio-alto. Se seleccionaron de manera no probabilística, por conveniencia, bajo los siguientes criterios de inclusión: tener o haber tenido una relación de pareja con una duración de al menos 1 mes, que las parejas fueran heterosexuales y, finalmente, que los participantes se encontraran en un rango de edad entre los 18 y los 25 años (ver tabla 1 ).

Tabla 1.

Distribución de los participantes por área de conocimiento

\begin{tabular}{cc}
\hline \multicolumn{2}{c}{ Distribución de la muestra por área de conocimiento } \\
\hline Área de la salud & 131 \\
\hline Área de ciencias sociales & 47 \\
\hline Área económico-administrativa & 24 \\
\hline Área de ciencias e ingeniería & 37 \\
\hline Área de artes y humanidades & 60 \\
\hline
\end{tabular}

\section{Instrumentos}

\section{Cuestionario de cyberbullying.}

Evaluado a través del Cuestionario de cyberbullying [CBQ] originalmente desarrollado por Calvete, Estévez, Villardón \& Padilla (2010) y adaptado para población mexicana por GámezGuadix, Villa-George \& Calvete (2014). La versión adaptada de este instrumento consta de 14 ítems para el factor de perpetración y 14 ítems para el factor de victimización. Se trata de una escala tipo Likert relacionada con la frecuencia de ocurrencia de cada afirmación y cuyo rango de respuestas se expresa de la siguiente manera: $0=N u n c a, 1=1$ o 2 veces, $2=3$ o 4 veces, $3=5$ o más 
veces. El índice de confiabilidad obtenido del instrumento completo de acuerdo con los autores fue de $\alpha=.85$

\section{Cuestionario de abuso on-line en el noviazgo (CAON).}

Se evaluó mediante la utilización del Cuestionario de Abuso On-line en el Noviazgo (CAON; Borrajo, Gámez-Guadix, Pereda \& Calvete, 2015), el cual consta de 20 ítems y cuyo objetivo es obtener el índice de dos variables principales; control y agresión física dentro de las relaciones de noviazgo. El método de evaluación es una escala de tipo Likert que consta del 1 al 6 siendo: $1=$ Nunca, $2=$ No en el último año, pero si anteriormente, 3=Rara vez, Ha ocurrido en 1 o 2 ocasiones, $4=A$ veces, Ha ocurrido entre 3 y 10 veces, $5=$ Con frecuencia, Ha ocurrido entre 11 y 20 ocasiones, $6=$ Casi siempre, Más de 20 veces. Con respecto a los Alfas obtenidos por el autor para este instrumento se presenta que para la variable de perpetración obtuvo un $\alpha=.73-.84$ mientras que la variable de victimización obtuvo un $\alpha=.81-.87$, es de importancia mencionar que dichos valores corresponden con la estandarización para población española.

\section{Procedimiento}

En primer lugar, se integró el Cuestionario de cyberbullying y el Cuestionario de Agresión Online en el Noviazgo en una sola batería, dentro de la plataforma Google Forms. La misma se componía en primer lugar del consentimiento informado, expresando el objetivo y las medidas de privacidad de los datos, su aceptación era requisito indispensable e ineludible para proseguir con el cuestionario. A continuación, se inició con la escala de cyberbullying, seguida por la escala de ciberviolencia de pareja y al finalizar un espacio designado para los participantes que tuvieran dudas o comentarios acerca del estudio.

Una vez se alojó el cuestionario dentro de Google Forms, se contactó a los participantes por medio de correo electrónico invitándolos a participar en el estudio y anexo se encontraba la liga para acceder al formulario. En caso de no desear participar en el estudio, el cuestionario redirigía a los sujetos a un apartado de agradecimiento y se daba por terminado el formulario.

\section{Aspectos éticos.}

La investigación fue revisada, dictaminada y aprobada por el Comité de bioética de la universidad privada donde ser realizó la recogida de datos, añadido a ello se consideró y respetó lo sugerido por la Declaración de Helsinki, el Código ético de la APA (2017) y la Sociedad Mexicana de Psicología (2010) en cuanto la realización de investigaciones psicológicas con seres humanos, así mismo el tratamiento de los datos anónimos y voluntarios ha sido confidencial.

\section{Resultados}

\section{Pruebas de fiabilidad y normalidad de la muestra}

Con el propósito de conocer si la distribución de la muestra era normal y para probar la fiabilidad de cada factor, se realizaron pruebas de Alfa de Cronbach segmentadas por sexo. Como es posible observar a continuación, los índices de confiabilidad para cada factor son considerablemente elevados con puntajes $\alpha$ por encima de 0.7 , lo que puede ser interpretado como una alta confiabilidad para los propósitos de la presente investigación. A continuación, se procedió con pruebas de normalidad con el índice Kolmogórov-Smirnov. Acorde con los resultados obtenidos y presentados en la Tabla 2, se puede concluir los datos obtenidos no se distribuyen de manera normal. 
Tabla 2.

Pruebas de confiabilidad por factor, segmentado por sexo

\begin{tabular}{cccc}
\hline Factor & Sig. K-S & Sexo & $\alpha$ \\
\hline \multirow{2}{*}{ Acoso cibernético sufrido } & .000 & Mujeres & 0.73 \\
\cline { 2 - 4 } & .000 & Hombres & 0.87 \\
\hline \multirow{2}{*}{ Acoso cibernético cometido } & .000 & Mujeres & 0.72 \\
\cline { 2 - 4 } Ciberviolencia - control sufrido & .000 & Hombres & 0.858 \\
\cline { 2 - 4 } & .000 & Mujeres & 0.851 \\
\hline \multirow{2}{*}{ Ziberviolencia - control cometido } & .000 & Hombres & 0.82 \\
\cline { 2 - 4 } Ciberviolencia - agresión directa & .000 & Mujeres & 0.861 \\
\cline { 2 - 4 } sufrida & .000 & Hombres & 0.9 \\
\hline Ciberviolencia - agresión directa & .000 & Mujeres & 0.848 \\
\cline { 2 - 4 } cometida & .000 & Hombres & 0.728 \\
\cline { 2 - 4 } & .000 & Mujeres & 0.809 \\
\hline
\end{tabular}

Nota: Sig K-S = índice Kolmogorov-Smirnov. $\alpha=$ índice Alfa de Cronbach

\section{Análisis descriptivos}

Una vez realizada la comprobación con respecto a la distribución de la muestra y la fiabilidad de las variables, se procedió con el acercamiento al primer objetivo, identificar cuáles son las conductas que se presentan con mayor y menor frecuencia, tanto en hombres como en mujeres, en ambos fenómenos. Para ello, se elaboraron Tablas descriptivas de frecuencia por cada ítem que componen las escalas implementadas en este estudio y segmentadas por sexo (véanse Tablas 3 a 6$)$.

\section{Prevalencia y frecuencia de cyberbullying}

En primer lugar, se presentan las Tablas de frecuencia relacionadas con conductas de cyberbullying (Tablas 3 y 4 ).

Comenzando con las conductas sufridas, se segmentó cada ítem por sexo y se describió la frecuencia de cada conducta. Los hallazgos indicaron que el ítem menos recurrente en el caso de las mujeres fue el no. 14 a. Mientras que el ítem con mayor frecuencia fue el no. 1a.

En lo que respecta a los hombres, los ítems menos frecuentes fueron el no. 9.a y el no. 14 a. Por otro lado, los ítems que presentaron mayor frecuencia son el no. 4 a. y el no. 12.a. 
Tabla 3.

Distribución de frecuencias por ítem cyberbullying sufrido

\begin{tabular}{|c|c|c|c|c|c|c|c|c|c|}
\hline \multirow{2}{*}{ Ítem } & \multirow{2}{*}{ Sexo } & \multicolumn{2}{|c|}{0} & \multicolumn{2}{|r|}{1} & \multicolumn{2}{|c|}{2} & \multicolumn{2}{|c|}{3} \\
\hline & & $\mathrm{F}$ & $\mathrm{P}$ & $\mathrm{F}$ & $\mathrm{P}$ & $\mathrm{F}$ & $\mathrm{P}$ & $\mathrm{F}$ & $\mathrm{P}$ \\
\hline \multirow{2}{*}{$1 \mathrm{a}$} & $\mathbf{M}^{* *}$ & 130 & 71 & 37 & 20.2 & 14 & 7.7 & 2 & 1.1 \\
\hline & $\mathrm{H}$ & 83 & 71.6 & 29 & 25 & 4 & 3.4 & - & - \\
\hline \multirow{2}{*}{$2 a$} & $\mathrm{M}$ & 155 & 84.7 & 26 & 14.2 & 2 & 1.1 & - & - \\
\hline & $\mathrm{H}$ & 99 & 85.3 & 17 & 14.7 & - & - & - & - \\
\hline \multirow{2}{*}{$3 \mathrm{a}$} & $\mathrm{M}$ & 169 & 92.3 & 11 & 6 & 3 & 1.6 & - & - \\
\hline & $\mathrm{H}$ & 101 & 87.1 & 12 & 10.3 & 3 & 2.6 & - & - \\
\hline \multirow{2}{*}{$4 \mathrm{a}$} & $\mathrm{M}$ & 136 & $\begin{array}{l}74.3 \\
\end{array}$ & 34 & 18.6 & 12 & 6.6 & 1 & .5 \\
\hline & $\mathrm{H}^{* *}$ & 85 & 73.3 & 25 & 21.6 & 3 & 2.6 & 3 & 2.6 \\
\hline \multirow{2}{*}{$5 \mathrm{a}$} & $\mathrm{M}$ & 159 & 86.9 & 16 & 8.7 & 8 & 4.4 & - & - \\
\hline & $\mathrm{H}$ & 101 & 87.1 & 14 & 12.1 & 1 & .9 & - & - \\
\hline \multirow{2}{*}{$6 \mathrm{a}$} & $\mathrm{M}$ & 164 & 89.6 & 14 & 7.7 & 4 & 2.2 & 1 & .5 \\
\hline & $\mathrm{H}$ & 97 & 83.6 & 19 & 16.4 & - & - & - & - \\
\hline \multirow{2}{*}{$7 \mathrm{a}$} & $\mathrm{M}$ & 179 & 97.8 & 3 & 1.6 & - & - & 1 & .5 \\
\hline & $\mathrm{H}$ & 107 & 92.2 & 9 & 7.8 & - & - & - & - \\
\hline \multirow[b]{2}{*}{$8 \mathrm{a}$} & $M$ & 177 & 96.7 & 5 & 2.7 & 1 & .5 & - & - \\
\hline & $\mathrm{H}$ & 103 & 88.8 & 12 & 10.3 & 1 & .9 & - & - \\
\hline \multirow{2}{*}{$9 \mathrm{a}$} & $\mathrm{M}$ & 182 & 99.5 & - & - & 1 & .5 & - & - \\
\hline & $\mathrm{H}^{*}$ & 108 & \begin{tabular}{|c|}
93.1 \\
\end{tabular} & 8 & 6.9 & - & - & - & - \\
\hline \multirow{2}{*}{$10 \mathrm{a}$} & $\mathrm{M}$ & 180 & 98.4 & 2 & 1.1 & - & - & 1 & .5 \\
\hline & $\mathrm{H}^{*}$ & 108 & 93.1 & 8 & 6.9 & - & - & - & - \\
\hline \multirow{2}{*}{$11 \mathrm{a}$} & $\mathrm{M}$ & 165 & 90.2 & 12 & 6.6 & 5 & 2.7 & 1 & .5 \\
\hline & $\mathrm{H}$ & 105 & 90.5 & 9 & $\begin{array}{l}7.8 \\
\end{array}$ & 1 & .9 & 1 & .9 \\
\hline \multirow{2}{*}{$12 \mathrm{a}$} & $M$ & 154 & 84.2 & 25 & 13.7 & 3 & 1.6 & 1 & .5 \\
\hline & $\mathrm{H}^{* *}$ & 93 & 80.2 & 19 & 16.4 & 1 & .9 & 3 & 2.6 \\
\hline \multirow{2}{*}{$13 \mathrm{a}$} & $\mathrm{M}$ & 181 & 98.9 & 1 & .5 & 1 & .5 & - & - \\
\hline & $\mathrm{H}$ & 113 & 97.4 & 3 & 2.6 & - & - & - & - \\
\hline \multirow{2}{*}{$14 \mathrm{a}$} & $\mathrm{M}^{*}$ & 183 & 100 & - & - & - & - & - & - \\
\hline & $\mathrm{H}$ & 106 & 91.4 & 10 & 8.6 & - & - & - & - \\
\hline
\end{tabular}

Nota: * Refiere a los ítems con menor frecuencia. ** Refiere a los ítems con mayor frecuencia. $\mathrm{F}=$ Frecuencia. $\mathrm{P}=$ Porcentaje. $\mathbf{0}=$ Nunca. $\mathbf{1 = 1}$ a 2 veces. $\mathbf{2}=3$ a 4 veces. $\mathbf{3 = 5}$ o más veces. 1a: "Enviarme mensajes amenazantes o insultantes.", 2a: "Subir o enviar imágenes mías que pueden ser humillantes.", 3a: "Poner enlaces a imágenes humillantes mías para que las vean otras personas.", 4a: "Escribir o difundir bromas, rumores, chismes o comentarios que me ponían en ridículo.", 5a: "Subir enlaces donde aparecian rumores, chismes etc. sobre mi para que las leyeran otras personas.”, 6a: “Conseguir mi contraseña para acceder a redes sociales (nicks, claves, etc.) y enviar mensajes en mi nombre que me podian hacer quedar mal ante los demás o crearme problemas con mis conocidos.", 7a: "Grabarme en vídeo o tomarme fotografías con el móvil mientras un grupo se ríe y me obliga a hacer algo humillante o ridiculo.", 8a: “Subir esas imágenes mías en las redes sociales para las puedan ver otras personas. ”, 9a: "Grabarme en vídeo o tomarme fotografías con el móvil mientras alguien me golpea o me hace daño.", 10a: “Subir esas imágenes mías grabadas en las redes sociales para las puedan ver otras personas.”, 11a: “Difundir secretos, información o imágenes comprometidas sobre mí.", 12a: “Apartarme de modo intencional de un grupo en una red social (chats, listas de amigos, foros temáticos, etc.).", 13a: “Grabarme en vídeo o tomarme fotografías mostrando algún tipo de comportamiento de índole sexual.", 14a: "Subir enlaces a imágenes mías mostrando comportamientos de índole sexual para que otras personas las vean"

Continuando, con lo que respecta a las frecuencias relacionadas con la variable de cyberbullying cometido, se halló que, en el caso de las mujeres, los ítems menos frecuentes fueron los reactivos $9 \mathrm{~b}, 10 \mathrm{~b}$ y 14 b. Con respecto al ítem más frecuente se halló que fue el no. 2 b. 
Siguiendo la misma dinámica, los hombres reportaron que, el ítem menos frecuente fue el no. 14 b. Mientras el ítem que se reportó con la frecuencia más elevada fue el no. 4 b.

Tabla 4.

Distribución de frecuencias por item cyberbullying cometido

\begin{tabular}{|c|c|c|c|c|c|c|c|c|c|}
\hline \multirow{2}{*}{ Ítem } & \multirow{2}{*}{ Sexo } & \multicolumn{2}{|c|}{0} & \multicolumn{2}{|c|}{1} & \multicolumn{2}{|c|}{2} & \multicolumn{2}{|c|}{3} \\
\hline & & $\mathrm{F}$ & $P$ & $\mathrm{~F}$ & $\mathrm{P}$ & $\mathrm{F}$ & $P$ & $\mathrm{~F}$ & $P$ \\
\hline \multirow{2}{*}{$1 \mathrm{~b}$} & $\mathrm{M}$ & 168 & 91.8 & 14 & 7.7 & 1 & .5 & - & - \\
\hline & $\mathrm{H}$ & 106 & 91.4 & 10 & 8.6 & - & - & - & - \\
\hline \multirow{2}{*}{$2 \mathrm{~b}$} & $\mathrm{M}^{* *}$ & 166 & 90.7 & 14 & 7.7 & 2 & 1.1 & 1 & .5 \\
\hline & $\mathrm{H}$ & 104 & 89.7 & 12 & 10.3 & - & - & - & - \\
\hline \multirow{2}{*}{$3 \mathrm{~b}$} & $\mathrm{M}$ & 174 & 95.1 & 7 & 3.8 & 2 & 1.1 & - & - \\
\hline & $\mathrm{H}$ & 106 & 91.4 & 8 & 6.9 & 2 & 1.7 & - & - \\
\hline \multirow{2}{*}{$4 \mathrm{~b}$} & $\mathrm{M}$ & 164 & 89.6 & 16 & 8.7 & 3 & 1.6 & - & - \\
\hline & $\mathrm{H}^{* *}$ & 98 & 84.5 & 16 & 13.8 & 1 & .9 & 1 & .9 \\
\hline \multirow{2}{*}{$5 \mathrm{~b}$} & $\mathrm{M}$ & 178 & 97.3 & 3 & 1.6 & 2 & 1.1 & - & - \\
\hline & $\mathrm{H}$ & 109 & 94 & 7 & 6 & - & - & - & - \\
\hline \multirow[b]{2}{*}{$6 \mathrm{~b}$} & $\mathrm{M}$ & 180 & 98.4 & 3 & 1.6 & - & - & - & - \\
\hline & $\mathrm{H}$ & 108 & 93.1 & 8 & 6.9 & - & - & - & - \\
\hline \multirow{2}{*}{$7 \mathrm{~b}$} & $\mathrm{M}$ & 180 & 98.4 & 2 & 1.1 & 1 & .5 & - & - \\
\hline & $\mathrm{H}$ & 109 & 94 & 6 & 5.2 & - & - & 1 & .9 \\
\hline \multirow{2}{*}{$8 \mathrm{~b}$} & $\mathrm{M}$ & 181 & 98.9 & 2 & 1.1 & - & - & - & - \\
\hline & $\mathrm{H}$ & 110 & 94.8 & 5 & 4.3 & - & - & 1 & .9 \\
\hline \multirow{2}{*}{$9 \mathrm{~b}$} & $\mathrm{M}^{*}$ & 182 & 99.5 & 1 & .5 & - & - & - & - \\
\hline & $\mathrm{H}$ & 110 & 94.8 & 5 & 4.3 & - & - & 1 & .9 \\
\hline \multirow{2}{*}{$10 \mathrm{~b}$} & $\mathrm{M}^{*}$ & 182 & 99.5 & 1 & .5 & - & - & - & - \\
\hline & $\mathrm{H}$ & 111 & 95.7 & 4 & 3.4 & - & - & 1 & .9 \\
\hline \multirow{2}{*}{$11 \mathrm{~b}$} & $\mathrm{M}$ & 176 & 96.2 & 6 & 3.3 & 1 & .5 & - & - \\
\hline & $\mathrm{H}$ & 111 & 95.7 & 5 & $\begin{array}{l}3.5 \\
4.3\end{array}$ & - & - & - & - \\
\hline \multirow{2}{*}{$12 \mathrm{~b}$} & $\mathrm{M}$ & 167 & 91.3 & 9 & 4.9 & 7 & 3.8 & - & - \\
\hline & $\mathrm{H}$ & 104 & 89.7 & 10 & 8.6 & 1 & .9 & 1 & .9 \\
\hline \multirow{2}{*}{$13 \mathrm{~b}$} & $\mathrm{M}$ & 181 & 98.9 & 2 & 1.1 & - & - & - & - \\
\hline & $\mathrm{H}$ & 112 & 96.6 & 4 & 3.4 & - & - & - & - \\
\hline \multirow{2}{*}{$14 \mathrm{~b}$} & $\mathrm{M}^{*}$ & 182 & 99.5 & 1 & .5 & - & - & - & - \\
\hline & $\mathrm{H}^{*}$ & 113 & 97.4 & 3 & 2.6 & - & - & - & - \\
\hline
\end{tabular}

Nota: * Refiere a los ítems con menor frecuencia. ** Refiere a los ítems con mayor frecuencia. $\mathrm{F}=$ Frecuencia. $\mathrm{P}=$ Porcentaje. $\mathbf{0}=$ Nunca. 1=1 a 2 veces. $\mathbf{2}=3$ a 4 veces. $\mathbf{3}=5$ o más veces. 1b: "Enviar mensajes amenazantes o insultantes a otras personas.", 2b: "Subir o enviar imágenes de un conocido que pueden ser humillantes.”, 3b: “Poner enlaces a imágenes humillantes de conocidos para que las puedan ver otras personas.”, 4b: "Escribir bromas, rumores, chismes o comentarios que ponían en ridículo a un compañero.”, 5b: "Subir enlaces donde aparecían rumores, chismes etc. de un compañero para que las leyeran otras personas.”, 6b: “Conseguir la contraseña de otra persona para acceder a redes sociales (nicks, claves, etc.) y enviar mensajes en su nombre que le podían hacer quedar mal ante los demás o crearle problemas con sus conocidos.", 7b: "Grabar vídeos o tomar fotografías con el móvil mientras un grupo se ríe y obliga a otra persona a hacer algo humillante o ridículo.", 8b: "Subir esas imágenes en redes sociales para que las puedan ver otras personas.", 9b: "Grabar vídeos o tomar fotografías con el móvil mientras alguien golpea o hace daño a otra persona.”, 10b: “Subir esas imágenes grabadas en redes sociales para que las vean otras personas.", 11b: "Difundir secretos, información o imágenes comprometidas de alguien.”, 12b: “Apartar a alguien de modo intencional de un grupo en una red social (chats, listas de amigos, foros temáticos, etc.).”, 13b: “Grabar vídeos o tomar fotografías a algún compañero/a en algún tipo de comportamiento de índole sexual para colgarlas o enviarlas.", 14b: "Subir enlaces a imágenes de conocidos mostrando comportamientos de índole sexual para que otras personas las vean." 


\section{Prevalencia y frecuencia de ciberviolencia de pareja}

En segundo lugar, se presentan las Tablas 5 y 6 correspondientes a la frecuencia de conductas de ciberviolencia sufrida y cometida respectivamente.

Aludiendo a los ítems relacionados con ciberviolencia sufrida (Tabla 5) y comenzando con las respuestas de las mujeres, el ítem que se presenta con menos frecuencia fue el número $12 \mathrm{a}$; aunque, de igual forma, resulta relevante considerar los ítems 4 a y 14 a. Mientras que el ítem que presentó mayor frecuencia fue el no. 7 a.

Consiguientemente, se presentan los ítems que reportaron menor frecuencia en el caso de los hombres fueron el no. 12 a. y el no. 3 a. Mientras que los ítems que presentaron una mayor frecuencia fueron el no. 13 a, 7 a, 11 a y 16 a.

Tabla 5.

Distribución de frecuencias por ítem ciberviolencia sufrida.

\begin{tabular}{|c|c|c|c|c|c|c|c|c|c|c|c|c|c|}
\hline \multirow{2}{*}{ ítem } & \multirow{2}{*}{ Sexo } & \multicolumn{2}{|c|}{1} & \multicolumn{2}{|c|}{2} & \multicolumn{2}{|c|}{3} & \multicolumn{2}{|c|}{4} & \multicolumn{2}{|c|}{5} & \multicolumn{2}{|c|}{6} \\
\hline & & $\mathrm{F}$ & $\mathrm{P}$ & $\mathrm{F}$ & $\mathrm{P}$ & $\mathrm{F}$ & $\mathrm{P}$ & $\mathrm{F}$ & $\mathrm{P}$ & $\mathrm{F}$ & $\mathrm{P}$ & $\mathrm{F}$ & $\mathrm{P}$ \\
\hline \multirow{2}{*}{ 1.a } & $M$ & 160 & 87.4 & 10 & 5.5 & 8 & 4.4 & 2 & 1.1 & 1 & .5 & 2 & 1.1 \\
\hline & $\mathrm{H}$ & 98 & 84.5 & 6 & 5.2 & 8 & 6.9 & 3 & 2.5 & 1 & .9 & - & - \\
\hline \multirow{2}{*}{ 2.a } & $M$ & 176 & 96.2 & 3 & 1.6 & 3 & 1.6 & - & - & - & - & 1 & .5 \\
\hline & $\mathrm{H}$ & 110 & 94.8 & 3 & 2.5 & 1 & .9 & 1 & .9 & - & - & 1 & .9 \\
\hline \multirow{2}{*}{$3 . \mathrm{a}$} & $\mathrm{M}$ & 176 & 96.2 & 1 & .5 & 4 & 2.2 & - & - & 1 & .5 & 1 & .5 \\
\hline & $\mathrm{H}^{*}$ & 112 & 96.6 & 2 & 1.7 & 1 & .9 & - & - & 1 & .9 & - & - \\
\hline \multirow{2}{*}{ 4.a } & $\mathrm{M}^{*}$ & 177 & 96.7 & 4 & 2.2 & 1 & .5 & - & - & 1 & .5 & - & - \\
\hline & $\mathrm{H}$ & 108 & 93.1 & 5 & 4.3 & 2 & 1.7 & - & - & - & - & 1 & .9 \\
\hline \multirow{2}{*}{$5 . \mathrm{a}$} & $\mathrm{M}$ & 147 & 80.3 & 16 & 8.7 & 12 & 6.6 & 3 & 1.6 & 3 & 1.6 & 2 & 1.1 \\
\hline & $\mathrm{H}$ & 90 & 77.6 & 6 & 5.2 & 14 & 12.1 & 3 & 2.6 & 2 & 1.7 & 1 & .9 \\
\hline \multirow{2}{*}{$6 . \mathrm{a}$} & $\mathrm{M}$ & 173 & 94.5 & 6 & 3.3 & 4 & 2.2 & - & - & - & - & - & - \\
\hline & $\mathrm{H}$ & 107 & 92.2 & 3 & 2.6 & 2 & 1.7 & 2 & 1.7 & 1 & .9 & 1 & .9 \\
\hline \multirow{2}{*}{ 7.a } & $\mathbf{M}^{* *}$ & 145 & 79.2 & 15 & 8.2 & 10 & 5.5 & 6 & 3.3 & 3 & 1.6 & 4 & 2.2 \\
\hline & $\mathrm{H}^{* *}$ & 90 & 77.6 & 9 & 7.8 & 9 & 7.8 & 6 & 5.2 & - & - & 2 & 1.7 \\
\hline \multirow{2}{*}{ 8.a } & M & 174 & 95.1 & 5 & 2.7 & 2 & 1.1 & 2 & 1.1 & - & - & - & - \\
\hline & $\mathrm{H}$ & 110 & 94.8 & 4 & 3.4 & 2 & 1.7 & - & - & - & - & - & - \\
\hline \multirow{2}{*}{ 9.a } & $\mathrm{M}$ & 174 & 95.1 & 5 & 2.7 & 3 & 1.6 & 1 & .5 & - & - & - & - \\
\hline & $\mathrm{H}$ & 109 & 94 & 4 & 3.4 & 2 & 1.7 & - & - & - & - & 1 & .9 \\
\hline \multirow{2}{*}{ 10.a } & $\mathrm{M}$ & 167 & 91.3 & 4 & 2.2 & 10 & 5.5 & 2 & 1.1 & - & - & - & - \\
\hline & $\mathrm{H}$ & 100 & 86.2 & 8 & 6.9 & 4 & 3.4 & 1 & .9 & 3 & 2.6 & - & - \\
\hline \multirow[t]{2}{*}{ 11.a } & $\mathrm{M}$ & 119 & 65 & 35 & 19.1 & 14 & 7.7 & 10 & 5.5 & 3 & 1.6 & 2 & 1.1 \\
\hline & $\mathrm{H}^{* *}$ & 79 & 68.1 & 13 & 11.2 & 12 & 10.3 & 7 & 6 & 3 & 2.6 & 2 & 1.7 \\
\hline \multirow{2}{*}{ 12.a } & $\mathrm{M}^{*}$ & 177 & 96.7 & 2 & 1.1 & 3 & 1.6 & - & - & 1 & .5 & - & - \\
\hline & $\mathrm{H}^{*}$ & 112 & 96.6 & 1 & .9 & 1 & .9 & - & - & - & - & 2 & 1.7 \\
\hline \multirow{2}{*}{ 13.a } & $\mathrm{M}$ & 152 & 83.1 & 19 & 10.4 & 6 & 3.3 & 4 & 2.2 & 1 & .5 & 1 & .5 \\
\hline & $\mathrm{H}^{* *}$ & 100 & 86.2 & 6 & 5.2 & 6 & 5.2 & - & - & 1 & .9 & 3 & 2.6 \\
\hline \multirow{2}{*}{ 14.a } & $\mathrm{M}^{*}$ & 177 & 96.7 & 3 & 1.6 & 2 & 1.1 & - & - & - & - & 1 & .5 \\
\hline & $\mathrm{H}$ & 100 & 86.2 & 6 & 5.2 & 4 & 3.4 & 1 & .9 & 3 & 2.6 & 2 & 1.7 \\
\hline \multirow{2}{*}{ 15.a } & $\mathrm{M}$ & 171 & 93.4 & 5 & 2.7 & 6 & 3.3 & - & - & - & - & 1 & .5 \\
\hline & $\mathrm{H}$ & 105 & 90.5 & 4 & 3.4 & 2 & 1.7 & 3 & 2.6 & 1 & .9 & 1 & .9 \\
\hline
\end{tabular}




\begin{tabular}{cccccccccccccc}
\cline { 2 - 14 } 16.a & $\mathrm{M}$ & 159 & 86.9 & 9 & 4.9 & 10 & 5.5 & 4 & 2.2 & - & - & 1 & .5 \\
\cline { 2 - 14 } & $\mathrm{H}^{* *}$ & 98 & 84.5 & 6 & 5.2 & 7 & 6 & 3 & 2.6 & - & - & 2 & 1.7 \\
\cline { 2 - 14 } 17.a & $\mathrm{M}$ & 129 & 70.5 & 27 & 14.8 & 16 & 8.7 & 6 & 3.3 & 3 & 1.6 & 2 & 1.1 \\
\cline { 2 - 13 } & $\mathrm{H}$ & 82 & 70.7 & 11 & 9.5 & 12 & 10.3 & 8 & 6.9 & 2 & 1.7 & 1 & .9 \\
\cline { 2 - 13 } 18.a & $\mathrm{M}$ & 175 & 95.6 & 7 & 3.8 & 1 & .5 & - & - & - & - & - & - \\
\cline { 2 - 13 } & $\mathrm{H}$ & 104 & 89.7 & 5 & 4.3 & 5 & 4.3 & 1 & .9 & 1 & .9 & - & - \\
\cline { 2 - 13 } 19.a & $\mathrm{M}$ & 157 & 85.8 & 14 & 7.7 & 4 & 2.2 & 7 & 3.8 & - & - & 1 & .5 \\
\cline { 2 - 12 } & $\mathrm{H}$ & 95 & 81.9 & 11 & 9.5 & 5 & 4.3 & 2 & 1.7 & 1 & .9 & 2 & 1.7 \\
\cline { 2 - 13 } 20.a & $\mathrm{M}$ & 154 & 84.2 & 15 & 8.2 & 9 & 4.9 & 4 & 2.2 & - & - & 1 & .5 \\
\cline { 2 - 12 } & $\mathrm{H}$ & 89 & 76.7 & 7 & 6 & 11 & 9.5 & 6 & 5.2 & 2 & 1.7 & 1 & .9 \\
\hline
\end{tabular}

Nota: * Refiere a los ítems con menor frecuencia. ** Refiere a los ítems con mayor frecuencia. $\mathrm{F}=$ Frecuencia. $\mathrm{P}=$ Porcentaje. $\mathbf{1}=$ Nunca $. \mathbf{2}=$ No en el último año, pero sí anteriormente. $\mathbf{3}=$ Rara vez Ha ocurrido en 1 o 2 ocasiones. $\mathbf{4}=A$ veces. Ha ocurrido entre 3 y 10 veces. $\mathbf{5}=$ Con frecuencia. Ha ocurrido entre 11 y 20 ocasiones. $\mathbf{6}=$ Casi siempre. 1a: "Mi pareja o ex pareja ha controlado las actualizaciones de estado del muro de mi red social.", 2a: "Mi pareja o expareja me ha amenazado a través de las nuevas tecnologías en hacerme daño fisicamente.", 3a: "Mi pareja o expareja ha creado un perfil falso sobre mi en una red social para causarme problemas.", 4a: "Mi pareja o expareja ha escrito un comentario en el muro de una red social para insultarme o humillarme.", 5a: "Mi pareja o expareja ha utilizado mis contraseñas (teléfono, redes sociales, correo) para curiosear mis mensajes y/o contactos sin mi permiso.", 6a: "Mi pareja o expareja ha difundido secretos y/o informaciones comprometedoras sobre mí a través de las nuevas tecnologías.", 7a: "Mi pareja o expareja ha controlado la hora de mi última conexión en aplicaciones del móvil.", 8a: "Mi pareja o expareja me ha amenazado a través de las nuevas tecnologías con difundir secretos o información comprometedora sobre mí.", 9a: "Mi pareja o expareja ha utilizado las nuevas tecnologías para hacerse pasar por mi y crearme problemas.", 10a: "Mi pareja o expareja me ha enviado mensajes insultantes y/o humillantes a través de las nuevas tecnologías.", 11a: "Mi pareja o expareja ha revisado mis redes sociales, whatsapp o correo sin mi permiso.", 12a: "Mi pareja o expareja ha enviado y/o colgado fotos, imágenes y/o vídeos míos íntimos o de contenido sexual a otras personas sin mi permiso.", 13a: "Mi pareja o expareja ha utilizado las nuevas tecnologías para controlar dónde he estado y con quién.", 14a: "Mi pareja o ex pareja me ha amenazado a través de las nuevas tecnologías para que conteste a sus llamadas o mensajes de manera inmediata.", 15a: "Mi pareja o ex pareja se ha hecho pasar por otra persona a través de las nuevas tecnologías para ponerme a prueba.", 16a: "Mi pareja o ex pareja ha colgado música, poemas, frases... en los estados de su red social en referencia a mí con la intención de insultarme o humillarme.", 17a: "Mi pareja o expareja ha revisado mi teléfono móvil sin mi permiso.", 18a: "Mi pareja o expareja ha extendido rumores, chismes y/o bromas sobre mí a través de las nuevas tecnologías con la intención de ridiculizarme.", 19a: "Mi pareja o expareja me ha llamado de forma excesiva para controlar donde estaba y con quién.", 20a: "Mi pareja o expareja ha controlado las amistades que tengo en las redes sociales."

Consecuentemente se presentan las frecuencias relacionadas con los ítems de ciberviolencia cometida los resultados permiten vislumbrar los siguientes datos:

Para el segmento de las mujeres, el ítem que se presentó con menor frecuencia es el no. 8 b. Empero, el ítem que se presentó con mayor frecuencia fue el no. $5 \mathrm{~b}$.

Paralelamente el segmento correspondiente a los hombres arrojó los siguientes datos; el ítem que se presentó con menor frecuencia fue el no. 2 b. Mientras que el ítem con mayor frecuencia fue el no. $1 \mathrm{~b}$. 
Tabla 6.

Distribución de frecuencias por ítem ciberviolencia cometida

\begin{tabular}{|c|c|c|c|c|c|c|c|c|c|c|c|c|c|}
\hline \multirow{2}{*}{ Ítem } & \multirow{2}{*}{ Sexo } & \multicolumn{2}{|c|}{1} & \multicolumn{2}{|c|}{2} & \multicolumn{2}{|c|}{3} & \multicolumn{3}{|c|}{4} & \multicolumn{2}{|l|}{5} & \multirow{2}{*}{$\frac{6}{P}$} \\
\hline & & $\mathrm{F}$ & $\mathrm{P}$ & $\mathrm{F}$ & $\mathrm{P}$ & $\mathrm{F}$ & $\mathrm{P}$ & $\mathrm{F}$ & $\mathrm{P}$ & $\mathrm{F}$ & $\mathrm{P}$ & $\mathrm{F}$ & \\
\hline \multirow{2}{*}{ 1.b } & $\bar{M}$ & 165 & 90.2 & 9 & 4.9 & 7 & 3.8 & 1 & .5 & - & - & 1 & .5 \\
\hline & $\mathrm{H}^{* *}$ & 101 & 87.1 & 2 & 1.7 & 10 & 8.6 & - & - & 1 & .9 & 2 & 1.7 \\
\hline \multirow{2}{*}{ 2.b } & $\mathrm{M}$ & 179 & 97.8 & 1 & .5 & 3 & 1.6 & - & - & - & - & - & - \\
\hline & $\mathrm{H}^{*}$ & 115 & 99.1 & - & - & - & - & 1 & .9 & - & - & - & - \\
\hline \multirow{2}{*}{$3 . b$} & $\mathrm{M}$ & 177 & 96.7 & 3 & 1.6 & 2 & 1.1 & 1 & .5 & - & - & - & - \\
\hline & $\mathrm{H}$ & 114 & 98.3 & - & - & 1 & .9 & 1 & .9 & - & - & - & - \\
\hline \multirow{2}{*}{ 4.b } & $\mathrm{M}$ & 179 & 97.8 & 2 & 1.1 & 1 & .5 & 1 & .5 & - & - & - & - \\
\hline & $\overline{\mathrm{H}}$ & 111 & 95.7 & 2 & 1.7 & 2 & 1.7 & - & - & - & - & 1 & .9 \\
\hline \multirow{2}{*}{ 5.b } & $\mathbf{M}^{* *}$ & 150 & 82 & 18 & 9.8 & 9 & 4.9 & 2 & 1.1 & 1 & .5 & 3 & 1.6 \\
\hline & $\mathrm{H}$ & 96 & 82.8 & 7 & 6 & 10 & 8.6 & 2 & 1.7 & 1 & .9 & - & - \\
\hline \multirow{2}{*}{$6 . b$} & $M$ & 176 & 96.2 & 2 & 1.1 & 3 & 1.6 & 1 & .5 & - & - & 1 & .5 \\
\hline & $\mathrm{H}$ & 112 & 96.6 & 1 & .9 & 3 & 2.6 & - & - & - & - & - & - \\
\hline \multirow{2}{*}{ 7.b } & $\mathrm{M}$ & 137 & 74.9 & 20 & 10.9 & 17 & 9.3 & 3 & 1.6 & 4 & 2.2 & 2 & 1.1 \\
\hline & $\mathrm{H}$ & 93 & 80.2 & 9 & 7.8 & 10 & 8.6 & 3 & 2.6 & 1 & .9 & - & - \\
\hline \multirow{2}{*}{ 8.b } & $\mathrm{M}^{*}$ & 180 & 98.4 & 2 & 1.1 & 1 & .5 & - & - & - & - & - & - \\
\hline & $\mathrm{H}$ & 112 & 96.6 & 3 & 2.6 & 1 & .9 & - & - & - & - & - & - \\
\hline \multirow{2}{*}{ 9.b } & $\mathrm{M}$ & 178 & 97.3 & 2 & 1.1 & 2 & 1.1 & 1 & .5 & - & - & - & - \\
\hline & $\mathrm{H}$ & 109 & 94 & 6 & 5.2 & - & - & 1 & .9 & - & - & - & - \\
\hline \multirow{2}{*}{$10 . b$} & $\mathrm{M}$ & 171 & 93.4 & 5 & 2.7 & 6 & 3.3 & 1 & .5 & - & - & - & - \\
\hline & $\mathrm{H}$ & 103 & 88.8 & 9 & 7.8 & 3 & 2.6 & - & - & - & - & 1 & .9 \\
\hline \multirow{2}{*}{ 11.b } & $\mathrm{M}$ & 129 & 70.5 & 35 & 19.1 & 12 & 6.6 & 2 & 1.1 & 3 & 1.6 & 2 & 1.1 \\
\hline & $\mathrm{H}$ & 84 & 72.4 & 13 & 11.2 & 10 & 8.6 & 7 & 6 & 1 & .9 & 1 & .9 \\
\hline \multirow{2}{*}{$12 . b$} & $\mathrm{M}$ & 179 & 97.8 & 4 & 2.2 & - & - & - & - & - & - & - & - \\
\hline & $\mathrm{H}$ & 113 & 97.4 & 2 & 1.7 & - & - & - & - & 1 & .9 & - & - \\
\hline \multirow{2}{*}{ 13.b } & $\mathrm{M}$ & 154 & 84.2 & 19 & 10.4 & 7 & 3.8 & 1 & .5 & 1 & .5 & 1 & .5 \\
\hline & $\mathrm{H}$ & 96 & 82.8 & 13 & 11.2 & 4 & 3.4 & 1 & .9 & 1 & .9 & 1 & .9 \\
\hline $14 \mathrm{~h}$ & M & 178 & 97.3 & 2 & 1.1 & 1 & .5 & - & - & 1 & .5 & 1 & .5 \\
\hline & $\mathrm{H}$ & 105 & 90.5 & 6 & 5.2 & 2 & 1.7 & 1 & .9 & 2 & 1.7 & - & - \\
\hline $15 \mathrm{~h}$ & $\mathrm{M}$ & 171 & 93.4 & 6 & 3.3 & 5 & 2.7 & 1 & .5 & - & - & - & - \\
\hline $1 J .0$ & $\mathrm{H}$ & 110 & 94.8 & 3 & 2.6 & 1 & .9 & 2 & 1.7 & - & - & - & - \\
\hline & $\mathrm{M}$ & 161 & 88 & 15 & 8.2 & 6 & 3.3 & 1 & .5 & - & - & - & - \\
\hline 10.0 & $\mathrm{H}$ & 101 & 87.1 & 9 & 7.8 & 3 & 2.6 & 1 & .9 & 1 & .9 & 1 & .9 \\
\hline $17 \mathrm{~h}$ & $\mathrm{M}$ & 137 & 74.9 & 29 & 15.8 & 12 & 6.6 & 2 & 1.1 & 1 & .5 & 2 & 1.1 \\
\hline 17.0 & $\mathrm{H}$ & 88 & 75.9 & 12 & 10.3 & 9 & 7.8 & 5 & 4.3 & 1 & .9 & 1 & .9 \\
\hline 101 & $\mathrm{M}$ & 179 & 97.8 & 4 & 2.2 & - & - & - & - & - & - & - & - \\
\hline & $\mathrm{H}$ & 108 & 93.1 & 5 & 4.3 & 2 & 1.7 & - & - & 1 & .9 & - & - \\
\hline $10 \mathrm{~h}$ & $\mathrm{M}$ & 169 & 92.3 & 8 & 4.4 & 4 & 2.2 & - & - & - & - & 2 & 1.1 \\
\hline 17.0 & $\mathrm{H}$ & 98 & 84.5 & 11 & 9.5 & 4 & 3.4 & 1 & .9 & 2 & 1.7 & - & - \\
\hline 20 & $\mathrm{M}$ & 155 & 84.7 & 19 & 10.4 & 6 & 3.3 & 2 & 1.1 & 1 & .5 & - & - \\
\hline 20.0 & $\mathrm{H}$ & 96 & 82.8 & 9 & 7.8 & 7 & 6 & 1 & .9 & 3 & 2.6 & - & - \\
\hline
\end{tabular}


Nota: * Refiere a los ítems con menor frecuencia. ** Refiere a los ítems con mayor frecuencia. $\mathrm{F}=$ Frecuencia. $\mathrm{P}=$ porcentaje. $\mathbf{1}=$ Nunca $. \mathbf{2}=$ No en el último año, pero sí anteriormente. $\mathbf{3}=$ Rara vez Ha ocurrido en 1 o 2 ocasiones. 4=A veces. Ha ocurrido entre 3 y 10 veces. 5=Con frecuencia. Ha ocurrido entre 11 y 20 ocasiones. 6=Casi siempre. 1b: "He controlado las actualizaciones de estado del muro de la red social de mi pareja o ex pareja.", 2b: "He amenazado a mi pareja o expareja a través de las nuevas tecnologías con hacerle daño físicamente.", $\mathbf{3 b}$ : “He creado un perfil falso sobre mi pareja o expareja en una red social para causarle problemas." 4b: He escrito un comentario en el muro de una red social para insultar o humillar a mi pareja o expareja. 5b: “He utilizado las contraseñas (teléfono, redes sociales, correo) de mi pareja o expareja para curiosear sus mensajes y/o contactos sin su permiso." 6b: "He difundido secretos y/o informaciones comprometedoras sobre mi pareja o expareja a través de las nuevas tecnologías." 7b: "He controlado la hora de la última conexión de mi pareja o expareja en aplicaciones del móvil.”, 8b: “He amenazado a mi pareja o expareja a través de las nuevas tecnologías con difundir secretos o información comprometedora sobre él/ella.", 9b: “He utilizado las nuevas tecnologías para hacerme pasar por mi pareja o expareja y crearle problemas.”, 10b: “He enviado mensajes insultantes y/o humillantes a mi pareja o expareja a través de las nuevas tecnologías.", 11b: “He revisado las redes sociales, whatsapp o correo de mi pareja sin su permiso.”, 12b: “He enviado y/o colgado fotos, imágenes y/o vídeos de contenido sexual sobre mi pareja o expareja a otras personas sin su permiso.”, 13b: “He utilizado las nuevas tecnologías para controlar a mi pareja o expareja dónde ha estado y con quién." , 14b: “He amenazado a mi pareja o expareja a través de las nuevas tecnologías para que conteste a mis llamadas o mensajes de manera inmediata.", 15b: “Me he hecho pasar por otra persona a través de las nuevas tecnologías para poner a prueba a mi pareja o expareja.", 16b: “He colgado música, poemas, frases... en los estados de mi red social en referencia a mi pareja o expareja con la intención de insultarle o humillarle.", 17b: "He revisado el teléfono móvil de mi pareja o expareja sin su permiso.", 18b: "He extendido rumores, chismes y/o bromas a través de las nuevas tecnologías sobre mi pareja o expareja con la intención de ridiculizarla.”, 19b: “He llamado a mi pareja o expareja de forma excesiva para controlar donde estaba y con quién”, 20b: “He controlado las amistades que tiene mi pareja o expareja en las redes sociales."

\section{Análisis inferenciales}

Para la comprobación del tercer objetivo se realizaron los análisis inferenciales correspondientes para conocer las diferencias por sexo en cada variable evaluada.

A continuación, se presenta la Tabla 7 en la que se muestran estadísticos descriptivos ( $M d=$ Mediana, $D T=$ Desviación Típica; $R=$ Rango) seguido por los valores obtenidos a partir de la prueba $U$ de Mann Whitney.

Como se puede apreciar, se halló una diferencia significativa en lo que respecta a la variable de ciberviolencia, particularmente el factor agresión directa en la cual los hombres señalaron que tienden a sufrir con mayor frecuencia dicho tipo de conductas on-line que las mujeres.

Tabla 7.

Diferencias por sexo en cyberbullying y ciberviolencia sufrida

\begin{tabular}{c|cccccccccccc}
\hline & $M d$ & $D T$ & $R$ & $M d$ & $D T$ & $R$ & $U$ & $Z$ & $p$ & & $\eta^{2} P S_{\text {est }}$ \\
\hline & \multicolumn{3}{c}{ Hombres } & \multicolumn{3}{c}{ Mujeres } & & & & \\
\hline CB & .00 & 2.62 & 156.53 & .00 & 1.60 & 145.86 & 9857.00 & $\begin{array}{c}- \\
1.50\end{array}$ & .133 & $\begin{array}{c}- \\
0.07\end{array}$ & 0.49 \\
\hline CVC & 1.00 & .62 & 147.05 & 1.11 & .52 & 151.87 & 10272.00 & - & .504 & .614 & - \\
0.02 & 0.48 \\
\hline CVAD & 1.00 & .28 & 157.03 & 1.00 & .23 & 145.55 & 9799.00 & $\begin{array}{c}- \\
2\end{array}$ & .019 & - \\
0
\end{tabular}


Finalmente, la Tabla 8 presenta los valores obtenidos mediante el índice de correlación Rho de Spearman, para su presentación se destacan las asociaciones significativas más fuertes.

En ese sentido, las correlaciones más fuertes $(r h o=.735, p<0.01)$ se encuentran en la asociación entre la vivencia de ciberviolencia, en su modalidad de control, y la perpetración de ese mismo tipo de violencia en el grupo de las mujeres; esta misma situación puede encontrarse en la muestra de varones $(r h o=.712, p<0.01)$. En segundo lugar, se hallaron relaciones significativas entre la agresión directa sufrida y cometida $(r h o=.635, p<0.01)$ en las participantes, mientras que en los varones se halló una relación estadísticamente significativa entre el control sufrido y la agresión directa sufrida $(r h o=.611, p<0.01)$ así como el control tanto en su victimización como perpetración $(r h o=.640, p<0.01)$. Ya con menor fuerza en el índice de asociación, puede destacarse en la muestra de las féminas, la correlación entre cyberbullying cometido y sufrido ( $r h o=.494, p<0.01$ ), y en el caso de los participantes la relación entre la agresión directa sufrida y el control cometido ( $r h o=.473, p<0.01)$.

Tabla 8.

Asociaciones entre las diversas variables incluidas en el estudio

\begin{tabular}{ccccccc}
\hline & 1 & 2 & 3 & 4 & 5 & 6 \\
\hline 1 & - & $.408^{* *}$ & $.299 * *$ & $.295^{* *}$ & $.397 * *$ & $.298^{* *}$ \\
2 & $.494 * *$ & - & $191^{*}$ & .179 & .182 & $.289 * *$ \\
3 & $.192^{* *}$ & .136 & - & $.712 * *$ & $.611^{* *}$ & $.382^{* *}$ \\
4 & .123 & $.220^{* *}$ & $.735^{* *}$ & - & $.473^{* *}$ & $.454 * *$ \\
5 & $.353 * *$ & $.364 * *$ & $.462 * *$ & $.310 * *$ & - & $.640^{* *}$ \\
6 & $.232 * *$ & $.455^{* *}$ & $.278^{* *}$ & $.340 * *$ & $.635^{* *}$ & - \\
\hline
\end{tabular}

Nota. **La correlación significativa en el nivel 0.01 (bilateral), * 0.05 (bilateral). 1=Acoso cibernético sufrido, $\mathbf{2}=$ Acoso cibernético cometido, $\mathbf{3}=$ Ciberviolencia control sufrido, $\mathbf{4}=$ Ciberviolencia control cometido, $\mathbf{5}=$ Ciberviolencia agresión directa sufrida, $\mathbf{6}=$ Ciberviolencia agresión directa cometida. Los datos por debajo de la diagonal corresponden a las mujeres, los datos por encima de la diagonal corresponden a los de hombres.

\section{Discusión}

El presente estudio se encaminó a explorar si existe una relación entre tópicos conocidos como cyberbullying y ciberviolencia de pareja. Lo cual fue posible mediante los análisis de las conductas más frecuentes, las diferencias entre perpetración y victimización de ambas variables segmentadas por sexo y las correlaciones existentes entre las variables de cada fenómeno pareja en una muestra de jóvenes de una universidad privada del estado de Puebla.

Antes de comenzar la discusión es importante mencionar que la literatura disponible con respecto a ambos temas aún es limitada, particularmente en lo que concierne a poblaciones de adultos jóvenes y la correlación entre ambos fenómenos. De igual manera, es preciso reiterar que, por el momento, no existen teorías unificadas o globalmente aceptadas para los dos tópicos, se trata de generalizaciones empíricas (Hernández et al., 2014). Así, los resultados obtenidos con respecto a conductas tanto de cyberbullying como de ciberviolencia, muestran que aquellas conductas relacionadas con las variables de agresión directa y control son considerablemente más frecuentes, datos que concuerdan con las aportaciones realizadas por investigaciones similares (Borrajo et al., 2015; Lucio-López \& Prieto-Quezada, 2014; Zweig, Dank, Yahner \& Lachman, 
2013). Aunado a ello, no está de sobra enfatizar que ambos sexos señalaron con mayor frecuencia conductas de ciberviolencia en la pareja relacionadas con control sobre el otro miembro de la diada, resultados que concuerdan con lo encontrado por otros estudios con muestra de adolescentes (Hellevik, 2019) o universitarios (Burke, Wallen, Vail-Smith \& Knox, 2011). Estos hallazgos no son superfluos si se considera que este tipo de conductas suelen ser problemáticas ya que no se entienden como violentas e incluso se pueden justificar al entenderse como juego o "prueba de amor" (Flach \& Deslandes, 2017; 2019).

En segundo lugar, se buscó identificar la existencia de diferencias estadísticamente significativa entre las respuestas proporcionadas por hombres y mujeres con respecto la perpetración y la victimización de ambos fenómenos. Tal vez podría haberse esperado que las mujeres fueran quienes reportarían ser víctimas con mayor frecuencia de comportamientos de estos tipos de violencia, a la vez que serían ellas quienes las perpetrarían menos, y los hombres se percibirían mayormente como perpetradores (Verdejo, 2015). Empero, los resultados obtenidos no siguieron dicha línea ya que tanto hombres como mujeres reportaron ser víctimas y perpetradores de conductas de cyberbullying en medidas similares pues no se hallaron diferencias significativas en las variables analizadas, a excepción de la ciberviolencia, en la dimensión de agresión directa, donde los hombres, indicaron que sufren y cometen con mayor frecuencia este tipo de violencia (ataques a la persona, humillaciones, etc.). Estos hallazgos se encuentran en la línea de los obtenidos por García-Sánchez et al. (2017) y Stuart (2015), quienes sugieren que estos tipos particulares de violencia parecen tener una naturaleza mucho más bidireccional que unidireccional. Aunado a lo anterior, y bajo el supuesto de la ciberviolencia como una rama de la de la violencia de pareja, los resultados obtenidos concuerdan con lo propuesto por Rubio-Garay, López-Gonzáles, Carrasco \& Amor (2017) quienes explican que la violencia en pareja parece tener una naturaleza bidireccional.

Finalmente se buscó averiguar si existía correlación estadísticamente significativa entre ambos fenómenos. Al respecto es preciso recordar que parte de la literatura disponible se enfoca mayormente en las versiones off-line de dichas conductas, es decir, el cyberbullying es frecuentemente estudiado en relación con el bullying físico, tal como lo plantea Del Rey et al. (2012) quienes explican que existen una fuerte relación entre ambos, sin embargo, que es considerablemente más frecuente que se dé el salto de las conductas off-line a las condutas online, al grado de establecer que probablemente una pueda ser predictora de la otra, sin embargo, este fenómeno no parece desarrollarse a la inversa.. Lo mismo ocurre con la ciberviolencia pues de acuerdo con Backe et al. (2018) o Temple et al. (2016), parece existir una correlación positiva entre las conductas de violencia en la pareja off-line y la on-line. En ese orden de ideas, el presente estudio señala que tanto las variables de cyberbullying como de ciberviolencia de pareja en efecto se encuentran relacionadas entre sí de manera significativa, aunque la fuerza de asociación es baja; sin detrimento de ellos es conveniente decir que se hallaron fuertes correlaciones significativas entre la perpetración y recepción de conductas de cyberbullying y ciberviolencia de pareja, lo que podría sugerir un carácter bidireccional de estas conductas en ambos sexos, como se ha sugerido en otros estudios (Gámez-Guadix et al., 2018).

A manera de conclusión, tanto el cyberbullying como la ciberviolencia son fenómenos de reciente aparición, a pesar que existen diversos estudios al respecto, aún resulta complicado comprender sus alcances e incluso sus delimitaciones y caracterización, a pesar de ello la presente investigación permitió visualizar que, en efecto, existe correlación entre ambos fenómenos y parece tender a la bidireccionalidad; añadido a ello es preciso alertar de la posible normalización de estas conductas de violencia on-line (Martín, Pazos, Montilla \& Romero, 2016). En ese tenor, parece vislumbrarse un cambio generacional importante en la manera en la que jóvenes y adolescentes están interactuando, la influencia que el acceso a la internet y las TIC's están teniendo dentro de sus relaciones interpersonales y de pareja y como es que conductas que se encontraban limitadas por un tiempo y un espacio concretos ahora pueden desarrollarse prácticamente en cualquier momento o de manera constante. Aunado a esto, es posible suponer que puedan existir factores de riesgo más relevantes y con una relación más estrecha con la 
ciberviolencia de pareja. A pesar de que existió una relación entre el cyberbullying y ciberviolencia de pareja, ésta no fue lo. Por otra parte, la posible bidireccionalidad de la violencia puede ser el resultado de la convergencia tecnológica (Mitchell et al., 2017), sin embargo, también puede ser el resultado de factores sociales, cambios en los roles de género o, también sucede con el cyberbullying, el ser víctima de agresiones puede representar un factor de riesgo para que, a largo plazo, el individuo incurra en conductas de la misma índole (Del Rey et al., 2012). Todo ello implica riesgos y retos pues es muy posible que estos fenómenos continuarán e irán en aumento conforme la tecnología se vuelva cada vez más accesible y permita un mayor grado de interacción sin la necesidad de la interacción tradicional, cara a cara.

\section{Limitaciones del estudio}

Es importante considerar el tamaño y selección de la muestra, así como la distribución no equiparada por sexo, lo cual impide la generalización de los resultados a otras poblaciones y ámbitos universitarios ya que los participantes provenían de un contexto académico privado. Además, es necesario señalar que, en los instrumentos utilizados, el Cuestionario de Abuso Online en el Noviazgo (CAON) no se encuentra, hasta el momento, validado para población mexicana.

\section{Futuras líneas de investigación}

Los hallazgos de la presente investigación pueden representar un antecedente más en lo que respecta a estos fenómenos en el contexto mexicano, no obstante sería conveniente indagar aún más sobre la existencia y prevalencia de este tipo de conductas, para ello se exhortaría el estudio no solo en poblaciones urbanas sino también en poblaciones rurales, instituciones educativas públicas, la inclusión de parejas homosexuales, el desarrollo de instrumentos validados y adaptados específicamente para población mexicana; así como la realización de trabajos de naturaleza explicativa. Especialmente porque se trata de nuevas formas de violencia que parecen estar integrándose en la vida cotidiana de las y los jóvenes debido a la creciente inclusión de las Tecnologías de la Información y la Comunicación en la vida cotidiana de adolescentes y jóvenes.

\section{Referencias}

American Psychological Association (2017). Ethical Principles of Psychologists and Code of Conduct. Washington, DC: Autor. Recuperado de https://www.apa.org/images/ethicscode-2017_tcm7-218783.pdf

Backe, E.L., Lilleston, P. \& McCleary-Sills, (2018). Networked Individuals, Gendered Violence: A Literature Review of Cyberviolence. Violence and Gender, 5(3), 135-146.

Bernal, C. \& Angulo, F. (2013). Interacciones de jóvenes andaluces en las redes sociales. Revista científica de educomunicación, 20(40), 25-30.

Borrajo, E, \& Gámez-Guadix, M. (2016). Abuso “online” en el noviazgo: Relación con depresión, ansiedad y ajuste diádico. Behavioral Psychology/Psicología Conductual, 24(2), 221235.

Borrajo, E., Gámez-Guadix, M. \& Calvete, E. (2015). Cyberdating Abuse: Prevalence, context, and relationship with offline aggression. Psychological Reports: Relationships y Communications, 116(2), 565-585.

Borrajo, E., Gámez-Guadix, M., Pereda, N. \& Calvete, E. (2015). The development and validation of the cyber dating abuse questionnaire among young couples. Computers on Human Behavior, 48, 358-365.

Burke S.C., Wallen, M., Vail-Smith, K. \& Knox, D. (2011). Using technology to control intimate partners: An exploratory study of college undergraduates. Computers in Human Behavior, 27(3), 1162-1167.

Calvete, E., Orue, I., Estévez, A., Villardón, L. \& Padilla, P. (2010). Cyberbullying in adolescents: Modalities and aggressor's profile. Computers in Human Behavior, 26(5), 1128-1135. 
Cerezo-Ramírez, F. (2012). Bullying a través de las TIC. Boletín Científico Sapiens- Research, $2(2), 24-29$

Castellanos, V., Villa, F. \& Gámez-Guadix, M. (2016). Cyberbullying: Un problema de salud mental entre adolescentes mexicanos. Revista Especializada en Ciencias de la Salud, 19(1), 5-12.

Costa, T. \& Ferreira, S. (2018). Cyberbullying: Concepts, Dynamics, Characters and Health implications. Ciência y Saúde Coletiva, 23(10), 3369-3379.

Cowie, H. (2013). El impacto emocional y las consecuencias del Ciberacoso. CONVIVES, (3), 16-24.

Del Rey, R., Elipe, P. \& Ortega-Ruiz, R. (2012). Bullying and cyberbullying: Overlapping and predictive value of the co-occurrence. Psicothema, 24(4), 608-613.

Doucette, H., Collibee, C., Hood, E., Gittins, D., DeJesus, B. \& Rizzo, C. (2018). Perpetration of electronic intrusiveness among adolescent females: Associations with in-person dating violence. Journal of Interpersonal Violence. Advanced. doi: $10.1177 \% 2 \mathrm{~F} 0886260518815725$

Espinar, E. \& González, M.J. (2009). Jóvenes en las redes sociales virtuales. Un análisis exploratorio de las diferencias de género. Feminismos, 14, 87-106.

Flach, R.M.D. \& Deslandes, S.F. (2017). Cyber dating abuse in affective and sexual relationships: A literature review. Cadernos de Saúde Pública, 33(7), 1-18.

Flach, R.M.D. \& Deslandes, S.F. (2019). Cyber dating abuse or proof of love? The use of apps for surveillance and control in affective-sexual relations. Cadernos de Saúde Pública, $35(1), \mathrm{e} 00060118$.

Gámez-Guadix, M., Borrajo, E., \& Calvete, E. (2018). Abuso, control y violencia en la pareja a través de internet y los smartphones: características, evaluación y prevención. Papeles del Psicólogo, 39(3), 218-227.

Gámez-Guadix, M., Villa-George, F. \& Calvete, E. (2014). Psychometric properties of the Cyberbullying Questionnaire (CBQ) among Mexican students. Violence and Victims, 29(2), 232-245.

Garaigordobil, M. \& Aliri, J. (2013). Ciberacoso ("cyberbullying”) en el País Vasco: diferencias de sexo en víctimas, agresores y observadores. Psicología conductual, 21(3), 461-474.

García-Sánchez, P., Guevara-Martínez, C., Rojas-Solís, J., Peña-Cárdenas, F. \& González, V. (2017). Apego y ciber-violencia en la pareja de adolescentes. International Journal of Developmental and Educational Psychology, 2(1), 541-550.

Hellevik, M. (2019). Teenagers' personal accounts of experiences with digital intimate partner violence and abuse. Computers in Human Behavior, 92, 178-187.

Hernández, R., Fernández, C. \& Baptista, P. (2014). Metodología de la investigación. México D.F.: McGraw Hill

Hernández, M.A. \& Solano, I.M. (2007). Ciberbullying, un problema de acoso escolar. Revista Iberoamericana de Educación a Distancia, 10(1), 17-36.

López, E. K., Juárez, F., \& Acevedo, M. (2014). 1. Los pasos de un proyecto de investigación. En: F. Juárez, J. López, \& V. Salinas (Eds.), Apuntes para la investigación en salud (pp. 23-89). México, D. F.: PUIS y DGPFE, UNAM.

Lucio-López, L. \& Prieto-Quezada, M. (2014). Violencia en el ciberespacio en las relaciones de noviazgo adolescente. Un estudio exploratorio en estudiantes mexicanos de escuelas preparatorias. Revista de Educación y Desarrollo, 31, 61-72.

Martín, A., Pazos, M., Montilla, M. \& Romero, C. (2016). Una modalidad actual de violencia de género en parejas de jóvenes: Las redes sociales. Educación XX1, 19(2), 405-429.

Martínez-Otero, V. (2017). Acoso y ciberacoso en una muestra de alumnos de educación secundaria. Revista de Currículum y Formación de Profesorado, 21(3), 277-298.

Martínez-Ferrer, B. \& Moreno, D. (2017). Dependencia de las redes sociales virtuales y violencia escolar en adolescentes. International Journal of Developmental and Educational Psychology, 2(1), 105-114.

Mitchell, J., Tulane, S., Porter, B. \& Beckert, T. (2017). The perceived influence of media and technology and adolescent romantic relationships. Journal of Adolescent Research, 33(6), 1-21. 
Nobles, D.V., Londoño, L., Martínez, S., Ramos, A. A., Santa, G. P. \& Cortes, A.M. (2016). Tecnologías de la comunicación y relaciones interpersonales en jóvenes universitarios. Revista Educación y Humanismo, 18(30), 14-27.

Papalia, D., Feldman, R. \& Martorell, G. (2012). Desarrollo Humano. México. D.F: McGraw Hill.

Peter, I. \& Petermann, F. (2018). Cyberbullying: A concept analysis of defining attributes and additional influencing factors. Computers in Human Behavior, 89, 350-366.

Rodríguez, T. \& Rodríguez, Z. (2016). El amor y las nuevas tecnologías: experiencias de comunicación y conflicto. Comunicación y sociedad, (25), 15-41.

Rodríguez-Domínguez, C., Durán, M. \& Martínez-Pecino, R. (2017). Ciberagresores en el noviazgo adolescente y su relación con la violencia psicológica, el sexismo y los celos. Health and Addictions, 18(1), 17-27.

Rubio-Garay, F., López-Gonzáles M., Carrasco, M. \& Amor, J. (2017) Prevalencia de la violencia en el noviazgo: Una revisión sistemática. Papeles del Psicólogo/Psychologist Papers, $38(2), 1-13$.

Sautu, R., Boniolo, P., Dalle, P. \& Elbert, R. (2005). Manual de metodología. Construcción del marco teórico, formulación de los objetivos y elección de la metodología. Buenos Aires: CLACSO.

Sociedad Mexicana de Psicología (2010). Código Ético del Psicólogo. México, D.F.: Trillas.

Stuart, G. (2015). An Examination of the Partner Cyber Abuse Questionnaire in a College Student Sample. Psychology of violence, 6(1), 156-162.

Temple, J., Jeong, C., Brem, M., Wolford-Clevenger, C., Stuart, G., Fleschler, M. y Elmquist J. (2016). The Temporal Association Between Traditional and Cyber DatingAbuse Among Adolescents. Journal of Youth and Adolescence, 45, 340-349.

Vagi, K., O’Malley, E., Basile K. \& Vivolo-Kantor, A. (2015). Teen Dating Violence (Physical and Sexual) Among US High School Students: Findings From the 2013 National Youth Risk Behavior Survey. JAMA Pediatrics, 169(5), 474-482.

Verdejo, M. (2015). Ciberacoso y violencia de género en redes sociales. Sevilla: Universidad internacional de Andalucía

Yahner, J., Dank, M., Zweig, J. \& Lachman, P. (2014). The co-occurrence of physical and cyberdating violence and bullying among teens. Journal of Interpersonal Violence, 30(7), 1079-1089.

Zweig, J., Dank, M., Yahner, J. \& Pamela, L. (2013). The rate of Cyberdating abuse and how it relates to other forms of teen dating violence. Journal of Youth and Adolescence, 42, 1063-1077. 